\section{Liquor-Zellzählung, mikroskopisch}

T. O. Kleine

Institut für Laboratoriumsmedizin und Pathobiochemie, Molekulare Diagnostik Standort Marburg Referenzlabor für Liquordiagnostik, UKGM Universitätsklinikum Gießen und Marburg, Marburg, Deutschland

Synonym(e) Kammer-Zellzählung mit Liquor (CSF)

Englischer Begriff cell counting of cerebrospinal fluid (CSF)

Definition Visuelle Zählung und Differenzierung von Leukozyten und Erythrozyten in CSF mittels geeichter Zählkammer.

Physikalisch-chemisches Prinzip Visuelle Zellzählung mit Diskriminierung von Leukozyten und Erythrozyten nach Zellgröße, Form, Zellkern sowie Leukozytendifferenzierung in monokuleäre und polynukleäre Zellen mittels Beschaffenheit des Zellkerns, Kern/Zytoplasma-Verhältnis und Zytoplasmabeschaffenheit.

Verbesserung der Leukozyten-/Erythrozytenspezifität

- durch Zellkernanfärbung der Leukozyten mit Vitalfarbstoffen (Liquorzellvitalfärbung),

- durch Erythrozytenlyse mit verdünnter Essigsäure (1-3 mL Eisessig in $100 \mathrm{~mL}$ Aqua dest.).

Untersuchungsmaterial Präanalytik: Durchsichtige, farblose Polypropylen-Röhrchen, steril mit Verschluss.

Probenstabilität: Lagerung bei $4{ }^{\circ} \mathrm{C},<1-2$ Stunden, lichtgeschützt.

Entnahmebedingungen: $0,5 \mathrm{~mL}$ frischer Ventrikel-, Subokzipital-(SOP-), Lumbal-Liquor oder (subdurale) Zystenflüssigkeit.
Instrumentierung Geeichte Fuchs-Rosenthal-Zählkammer, Eppendorf-Mikropipetten und -Reaktionsgefäße für LiquorZellzählung mit Vitalfärbung, Mikroskop mit 40-facher Vergrößerung (Objektiv), ca. 400-fache Endvergrößerung.

Praktikabilität - Automatisierung - Kosten Schnelles, einfaches, manuelles Verfahren ohne großen technischen Aufwand bei geringer Probenzahl kostengünstig im Vergleich zu $\triangleright$ Liquor-Zellzählung, mechanisiert.

Bewertung - Methodenhierarchie (allg.) Mikroskopische Liquor-Zellzählung ist Teil von $>$ Liquor-Notfall-Programm, - Liquor-Basis-Programm und kann mechanisiert werden ( $\triangleright$ Liquor-Zellzählung, mechanisiert); s. Tabelle.

Referenzbereiche für frische Cerebrospinalflüssigkeit (1-2 Stunden alt):

\begin{tabular}{|l|l|l|l|}
\hline $\begin{array}{l}\text { Leukozyten } \\
\text { Erwachsene }\end{array}$ & $\begin{array}{l}\text { Liquor } \\
\text { Lumbal- (pro }\end{array}$ & $\begin{array}{l}\text { Subokzipital- } \\
(\text { pro } \mu \mathrm{L})\end{array}$ & $\begin{array}{l}\text { Ventrikel- (pro } \\
\mu \mathrm{L})\end{array}$ \\
\hline $\begin{array}{l}\text { Kinder } \\
\text { (Alter) }\end{array}$ & $\begin{array}{l}0-5 \\
0-1\end{array}$ & \\
\hline $\begin{array}{l}\text { 1. Monat } \\
\text { 2. Monat }\end{array}$ & $1-27$ & \\
\hline 3. Monat & $0-6$ & \\
\hline 4. Monat & $0-6$ & \\
\hline 5.-6. Monat & $0-11$ & \\
\hline 7.-12. & $0-5$ & \\
\hline $\begin{array}{l}\text { Monat } \\
\text { 2.-16. Jahr }\end{array}$ & $0-9$ & \\
\hline
\end{tabular}

Erythrozyten $0 / \mu \mathrm{l} \mathrm{CSF} ;<50 / \mu \mathrm{l}$ CSF gering artifiziell blutig

\section{Literatur}

Kleine TO (1984) Liquor. In: Thomas L (Hrsg) Labor und Diagnose. Indikation und Bewertung von Laborbefunden für die medizinische Diagnostik, 2. Aufl. TH-Books, Frankfurt am Main, S 939-940 